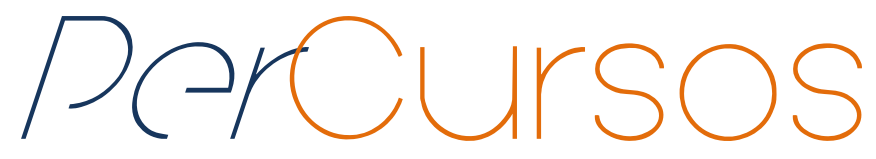

\title{
Escrita e criatividade na contextualização da Química ${ }^{1}$
}

\begin{abstract}
Resumo
A contextualização do conhecimento é um dos muitos objetivos do Ensino de Química. Através dela, é possível estabelecer relações com os diferentes fenômenos do cotidiano, o que permite uma aproximação maior entre o discente e a Química. O professor pode dispor de diferentes estratégias para alcançar a contextualização, entre elas estão as atividades escritas, que podem explorar diferentes gêneros: cartas, notícias, reportagens e entrevistas. A escrita ainda é pouco explorada nas aulas de Química, o que pode causar estranheza por parte dos alunos, quando lhes são propostas atividades desse tipo. Sendo assim, neste trabalho, apresentamos os resultados de um projeto desenvolvido no âmbito do PIBID, cujos objetivos se voltaram para a articulação entre criatividade e escrita para contextualizar a Química. Através dos textos entregues pelos discentes, pudemos conhecer as ideias prévias dos estudantes sobre o tema abordado; ajudá-los a compreender que a aprendizagem pode ocorrer tanto de forma tradicional quanto de maneira criativa, motivando-os na busca de novos meios para adquirir conhecimentos; promover reflexões sobre o caráter das soluções do cotidiano e suas propriedades; e desenvolver e valorizar habilidades próprias de cada estudante, por meios de diferentes produções textuais. Além de constituir um meio adequado para o aluno se apropriar dos conceitos adquiridos e ser capaz de aplicá-los em diferentes contextos e de nos ajudar a ressaltar a importância da escrita na construção do conhecimento.
\end{abstract}

Palavras-chave: Contextualização; Escrita; Criatividade; Cartas; Ensino de Química.

\author{
Isabela Marangon Christo Gatti \\ Licenciada em Química pela Univ. \\ Federal de Juiz de Fora - UFJF. \\ Mestranda em Química na UFJF. \\ Brasil \\ isagatti.quimica@gmail.com
}

\section{Andréia Francisco Afonso}

Doutora em Ciências pela Univ.

Federal de São Carlos - UFSCar.

Professora da Univ. Federal de Juiz de Fora - UFJF.

Brasil

andreia.afonso@ufjf.edu.br

\section{Priscilla Lucia Cerqueira}

Licenciada em Química pela Univ.

Federal de Juiz de Fora - UFJF.

Mestranda em Educação na UFJF.

Brasil

priquimica@hotmail.com

\section{Márcia Maria Pinto Coelho}

Licenciada em Química pela Univ.

Federal do Mato Grosso do Sul -

UFMS. Professora da Rede Estadual

de Ensino de Minas Gerais.

Brasil

marciacoelhodiverso@hotmail.com

\footnotetext{
${ }^{1}$ Subprojeto Química do Programa Institucional de Bolsa de Iniciação à Docência - PIBID, com apoio da Coordenação de Aperfeiçoamento de Pessoal de Nível Superior - CAPES/MEC.
} 


\title{
Writing and creativity in the contextualization of Chemistry
}

\begin{abstract}
The contextualization of knowledge is one of the many goals of the Chemistry Teaching. Through it, one can establish relationships with different everyday phenomena, which allows a closer relationship between the student and chemistry. The teacher may have different strategies to achieve the contextualization among them are the written activities, which can explore different genres: letters, news, reports and interviews. Writing is still little explored in chemistry classes, which may cause surprise by the students when they are proposed such activities. Thus, in this work we present the results of a project developed under the PIBID, whose objectives turned to the relationship between creativity and writing to contextualize Chemistry. Through the texts submitted by students, we know the previous ideas of students about the proposed theme; help them understand that learning can occur both in the traditional way as creatively motivating them to find new ways to acquire new knowledge; promote reflections on the nature of the everyday solutions and their properties; and develop and enhance each student own skills, by means of different textual productions. In addition, to be a good mean for the student to appropriate the acquired concepts and be able to apply them in different contexts and they help us to emphasize the importance of writing in the construction of knowledge.
\end{abstract}

Keywords: Contextualization; Written; Creativity; Letters; Chemistry Teaching.

\section{Para citar este artigo:}

GATTI, Isabela Marangon Christo; AFONSO, Andréia Francisco; CERQUEIRA, Priscilla Lucia; COELHO, Márcia Maria Pinto. Escrita e criatividade na contextualização da Química. Revista PerCursos, Florianópolis, v. 17, n.35, p. 140 -159, set./dez. 2016.

\section{DOI: $\mathbf{1 0 . 5 9 6 5 / 1 9 8 4 7 2 4 6 1 7 3 5 2 0 1 6 1 4 0}$}

http://dx.doi.org/10.5965/1984724617352016140 


\section{Introdução}

Atualmente, um dos muitos objetivos do Ensino de Química é contextualizar o conhecimento. É interessante perceber que a contextualização é recomendada nas Diretrizes Curriculares Nacionais da Educação Básica (BRASIL, 2013), como um meio de articular temas pelas suas interfaces podendo, assim, ser utilizada para concretizar uma proposta pedagógica interdisciplinar, por entender que

em relação à organização dos conteúdos, há necessidade de superar o caráter fragmentário das áreas, buscando uma integração no currículo que possibilite tornar os conhecimentos abordados mais significativos para os educandos e favorecer a participação ativa de alunos com habilidades, experiências de vida e interesses muito diferentes. (BRASIL, 2013, p. 118)

Nesse sentido, os movimentos de contextualização trazem consigo a intenção de romper as fronteiras fortemente demarcadas pelas disciplinas, proporcionando conexões e diálogos - não só entre conteúdos, mas também entre sujeitos -, o que consideramos essencial. E, como princípio norteador, nos guia a um Ensino de Química que busca estabelecer relações entre os conteúdos escolares e o cotidiano dos estudantes, tecendo reflexões, "o que significa um entendimento mais complexo do que a simples exemplificação do cotidiano ou mera apresentação superficial de contextos sem uma problematização que de fato provoque a busca de entendimentos sobre os temas de estudo" (WARTHA, SILVA e BEJARANO, 2013, p. 90).

$\mathrm{Na}$ dimensão da prática de sala de aula, atividades escritas podem ser propostas nas aulas de Química como um dos caminhos possíveis para contextualizar o conteúdo, bem como para o desenvolvimento da linguagem, que por sua vez é inerente ao desenvolvimento do pensamento.

É bem consolidado que o processo de ensino e aprendizagem é mediado pela linguagem, sendo esta, mobilizada a todo o tempo e de diversas maneiras pelos sujeitos. No cenário escolar, o ato de escrever é persistente e, ao longo dos anos, configurou-se como central na memorização de conteúdos. Os estudantes copiam aquilo que seus 
professores escrevem no quadro, transcrevem o que eles ditam, copiam fragmentos do livro no caderno, fazem provas. Além disso,

muitas vezes nas escolas os registros escritos merecem atenção apenas na hora da avaliação, e são classificados como certos ou errados. É muito raro que os professores solicitem aos estudantes, produções escritas que tenham objetivos além da repetição de conteúdos e conceitos já estabelecidos. (FLÔR, 2009, p. 33)

Nas aulas de Ciências observam-se metodologias muito fortemente direcionadas ao "fornecimento de respostas a questionários que exigem a reprodução de um texto base ou o preenchimento de lacunas em exercícios propostos para "reforçar" o conteúdo" (SOUZA e ALMEIDA, 2005, p. 367). Tal sistema, fortalecido ao longo dos anos finais do Ensino Fundamental, é muito naturalmente levado adiante para as aulas de Química, nas quais os discentes são mantidos sob a mesma lógica de aprendizagem. Ignorando-se, porém, que

pensamento e linguagem encontram-se imbricados - quando um deles é aprimorado, o outro quase sempre melhora. Assim, quando se solicita ao aluno que escreva algo, impinge-se a ele a tarefa de "pensar" sobre este assunto, pois o ato de escrever envolve muito mais do que simplesmente expor ideias armazenadas na cabeça. Para tanto, faz-se necessário que as ideias sejam repensadas e organizadas, para finalmente serem expostas. (QUEIROZ, 2001, p. 146)

Cabe então refletir sobre como é possível desenvolver o pensamento crítico na sala de aula sem que o estudante tenha espaço para escrever, numa escrita própria, sobre o que aprende. "No universo de discursos sobre a escola muito se tem falado sobre a importância da leitura, precisamos também pensar no importante papel que tem a escrita" (GIRALDI, 2010, p. 30). Estamos de acordo com Flôr (2009, p. 35), quando ela nos diz que "não dá para pensar a formação de um cidadão crítico sem que se dê a voz e a possibilidade de dizer aos estudantes", pois no ato de escrever reside potencial para 
questionar, buscar, entender e aprender acerca daquilo sobre o quê se escreve. Tomar a palavra é, sob essa luz, fundamental para desenvolver autonomia e criticidade, sendo que

a criticidade que entendemos como importante de ser trabalhada no contexto da educação em ciências escolar é a que busca construir leituras menos ingênuas, visa promover processos de educação por meio dos quais os sujeitos possam construir formas de participação social e mudanças. Assim, se faz necessário criar espaços nos quais os sujeitos sejam levados a trabalhar formas de leitura e de escrita que ampliem suas possibilidades de reflexão, tendo em vista a forte presença da ciência em nossas vidas na atualidade. (GIRALDI, 2010, p. 44)

Ademais, diversas pesquisas da área de ensino nos mostram que as metodologias que conduzem os estudantes à memorização são ineficazes para uma aprendizagem significativa, pois se constata que mesmo que os estudantes se tornem capazes de escrever a "resposta correta", muitas vezes não há real compreensão do fenômeno sobre o qual se está escrevendo e/ou não se consegue inferir sobre um contexto mais amplo. A questão da memorização se agrava quando o campo de conhecimento tem suas bases nas ciências exatas, como é o caso da Química, pois

de uma forma geral, enfatizam o desenvolvimento de habilidades quantitativas, como a efetuação de cálculos e resolução de problemas, em prejuízo do desenvolvimento de habilidades qualitativas, como a escrita. Além disto, o uso frequente da linguagem matemática por parte dos alunos conspira para que esta situação se fortaleça. (QUEIROZ, 2001, p. 143)

As habilidades quantitativas são essenciais para o desenvolvimento do conhecimento Químico, inclusive para entendermos a relação deste campo com outros e devem, sim, ser desenvolvidas no Ensino Médio. No entanto, a demasiada ênfase nestas habilidades se relaciona com as práticas que supervalorizam o conteúdo em detrimento do conhecimento. Ainda nesse cenário, à medida que o estudante vai passando pelos anos (séries) escolares, é atribuída cada vez menos importância para a criatividade. De 
fato, o valor do potencial criador do ser humano para a aprendizagem não é um conhecimento tão disseminado e, logo,

nos deparamos com a dificuldade na utilização do espaço escolar como local de desenvolvimento da criatividade, considerando que o sistema atual de ensino não favorece a formação de pessoas criativas, mas sim a repetição de informações por parte dos estudantes. (NAKANO, 2006, p. 206)

Alencar (2002, p. 166) aponta que as concepções acerca da criatividade quase sempre se mostram associadas a mitos como, por exemplo, a dicotomia do dom: a pessoa é criativa; a pessoa não é criativa. Acredita-se ainda que a maioria das pessoas é não criativa, sendo uma habilidade de poucos, que já nasceram com ela. Outra ideia apontada como comum pela autora é que "a expressão criativa ocorreria independentemente das condições ambientais, predominando uma concepção unilateral da criatividade, como um fenômeno eminentemente individual e intrapsíquico". No entanto, a realidade é que a criatividade é inerente ao ser humano e pode ser estimulada e desenvolvida, sendo todos criativos à sua própria maneira, de modo que a criatividade se apresenta em distintas formas e graus para diferentes pessoas e em diferentes situações. Vale ainda pontuar que

a extensão em que a criatividade floresce depende largamente do ambiente. [...] mesmo que a pessoa tenha todos os recursos internos necessários para pensar criativamente, sem algum apoio do ambiente dificilmente o potencial para criar que a pessoa traz dentro de si, se expressará. (ALENCAR, 2007, p. 47)

Com isso em mente, nos propusemos o desafio de desenvolver um projeto com propostas de atividades escritas e criativas, de autoria, sobre determinado conteúdo químico. "Tem a ver com nossa compreensão de ciência e como pensamos seu ensino. Sem negar o sedimentado, trabalhar sobre ele em busca de novas leituras, perspectivas e possibilidades" (FLÔR, 2009, p. 30). Tais atividades objetivaram estimular, pelo viés da 
escrita e da criatividade, a busca dos estudantes pela Química no cotidiano não só no campo da observação, mas também do entendimento, o que abarca seus questionamentos, habilidades e interesses pelo conhecimento e pelo mundo do qual somos parte.

\section{A intervenção didática}

Pontuamos, a seguir, as etapas de uma intervenção didática, realizada em outubro e novembro de 2015, com 71 estudantes de três turmas do terceiro ano do Ensino Médio, de uma escola da rede pública de ensino militar, parceira do subprojeto Química do PIBID ${ }^{2}$ da Universidade Federal de Juiz de Fora (UFJF).

Todas as atividades foram realizadas, no turno da manhã, pelas bolsistas e sob a supervisão da professora regente. O projeto surgiu na discussão dos resultados de uma intervenção anterior, na qual os estudantes expressaram dificuldades em escrever textos no formato de redação na aula de Química, o que nos conduziu ao desenvolvimento de atividades escritas com estas mesmas turmas, ainda no mesmo ano letivo.

Vale ressaltar que foi muito importante reservar um momento para que o grupo, formado por bolsistas de iniciação à docência e supervisora, pudesse discutir sobre as atividades e os resultados da intervenção anterior, porque além de permitir reflexões sobre as relações entre teoria e prática docente, nos ajudou a perceber e dialogar sobre os estudantes no sentido de entendê-los e não de julgá-los por não terem feito a atividade "corretamente" ou de culpabilizar professores e/ou escola.

Outro aspecto que consideramos importante destacar é que nossas reflexões sobre a importância da escrita para a formação dos estudantes do Ensino Médio foram cuidadosamente apresentadas a eles, turma a turma, estabelecendo um diálogo que foi muito positivo para nossas relações com as turmas. Fizemos isso para deixar claro que nos preocupamos genuinamente com a formação deles, e, portanto, gostaríamos de começar uma intervenção na qual eles fariam atividades escritas, sendo necessário saber

\footnotetext{
${ }^{2}$ Programa Institucional de Bolsa de Iniciação à Docência.
} 
o que os alunos pensavam sobre isso. O diálogo fluiu muito bem, o que nos deixou mais tranquilas ao longo do processo de pensar, propor, solicitar e auxiliar nas atividades que os estudantes nunca tinham feito em aulas de Química.

Definidas as direções pedagógicas e de ensino que gostaríamos de seguir, selecionamos o conteúdo curricular que engloba o conceito de potencial hidrogeniônico $(\mathrm{pH})$, devido à sua amplitude e às múltiplas relações com o cotidiano e com outros conhecimentos prévios - escolares ou não. Assim, concretizamos cinco encontros de 45 minutos com cada turma:

- $\quad 1^{\circ}$ Encontro: Aplicação de pré-teste. Para conhecer algumas ideias prévias a respeito dos conceitos de dissociação iônica, ionização, equilibro químico, pH, acidez e basicidade.

- $\quad \underline{2}^{\circ}$ Encontro: Experimentação. Para testar o $\mathrm{pH}$ de algumas soluções comerciais e outras feitas na UFJF, com papel indicador universal, papel de tornassol azul, papel de tornassol vermelho, e fenolftaleína. Também para testar o pH do vinagre antes e após diluição.

Selecionamos as soluções ${ }^{3}$ de acordo com três critérios: serão gerados diferentes resultados com os indicadores, a manipulação será segura, e algumas serão soluções usadas ou consumidas no dia-a-dia. A aula foi realizada no laboratório didático da escola e a turma foi disposta em dez grupos de, no máximo, quatro estudantes.

- $\quad 3^{\circ}$ Encontro: Aula expositiva dialógica 1. Houve discussão dos resultados do experimento, conduzindo questionamentos sobre a diferença, em nível molecular, entre soluções de $\mathrm{pH}$ diferentes. Em seguida, exploramos o nível representacional discutindo: auto-ionização da água; cálculo de $\mathrm{pH}, \mathrm{pOH}$, e das concentrações das espécies iônicas $\mathrm{H}^{+}$ $\left(\mathrm{H}_{3} \mathrm{O}^{+}\right)$e $\mathrm{OH}^{-}$; escala de $\mathrm{pH}$; acidez, alcalinidade e neutralidade. Finalizamos a aula realizando alguns exemplos destes cálculos.

- $\quad 4^{\circ}$ Encontro: Aula expositiva dialógica 2. Discussão sobre a natureza e o comportamento das substâncias indicadoras ácido-base, bem como do deslocamento do equilíbrio químico, quando na presença de outras substâncias de caráter ácido ou básico.

\footnotetext{
${ }^{3}$ Hidróxido de amônio $\left(\mathrm{NH}_{4} \mathrm{OH}\right)$ 1,7mol/L, cloreto de sódio $(\mathrm{NaCl}) 2 \mathrm{~g} / \mathrm{L}$, água, vinagre, multiuso, refrigerante e leite (mesmo que não seja conceituado como uma solução).
} 
- $\quad 5^{\circ}$ Encontro: Aplicação de pós-teste. Para verificar se as atividades realizadas levaram a uma mudança conceitual e ampliação dos conhecimentos dos estudantes acerca do $\mathrm{pH}$.

Solicitamos aos estudantes, atividades escritas, de autoria própria, somente no segundo e no terceiro encontros, para serem realizadas fora do horário de aula e entregues na aula seguinte, o que aconteceria no prazo de uma semana (QUADRO 1):

\begin{tabular}{|l|l|l|}
\hline Aula & $\begin{array}{l}\text { Gênero da atividade } \\
\text { escrita }\end{array}$ & Modo de realização \\
\hline Experimentação & $\begin{array}{l}\text { Tutorial ou relatório } \\
\text { científico }\end{array}$ & $\begin{array}{l}\text { Gênero escolhido por sorteio; para ser } \\
\text { feito e entregue em grupo }\end{array}$ \\
\hline $\begin{array}{l}\text { Aula expositiva } \\
\text { dialógica }\end{array}$ & $\begin{array}{l}\text { Notícia, reportagem, } \\
\text { entrevista ou carta }\end{array}$ & $\begin{array}{l}\text { Gênero escolhido pelo estudante; para } \\
\text { ser feito e entregue individualmente }\end{array}$ \\
\hline
\end{tabular}

Quadro 1 - Atividade escrita realizada e suas condições de realização.

Como os alunos ainda não tinham sido chamados a produzir estes gêneros nas aulas de Química, usamos o Facebook das turmas do $3^{\circ}$ ano para encaminhar algumas orientações quanto a essas atividades, buscando nós mesmas sermos criativas nas nossas produções textuais, entendendo que isso poderia estimular a criatividade da turma.

Entre os dois momentos de fazer as atividades houve uma diferença central: enquanto para os experimentos feitos no laboratório, a escrita foi mobilizada para relatar e discutir (relatório) ou descrever as etapas em um passo a passo (tutorial), para a aula expositiva foi pedido que eles escolhessem o gênero textual e usassem a criatividade para falar sobre situações que envolvem ácidos, bases e $\mathrm{pH}$. A atitude, proposital, tem a intenção de não delimitar o contexto, estimulando que o aluno direcione seu olhar para o cotidiano para perceber quais são as relações com o conteúdo estudado na aula, para aí então escrever no gênero de sua escolha. 


\section{Resultados e discussão}

Embora a intervenção exista como um todo - estando a etapa de experimentação associada ao cenário de contextualização, escrita e criatividade que nos dispusemos a estabelecer no projeto -, neste trabalho nos delimitaremos a discutir as atividades escritas dos gêneros notícia, reportagem, entrevista e carta. Daremos este enfoque porque, no formato em que foram propostas, estes gêneros exigiram mais dos estudantes, no que diz respeito à articulação do conteúdo com o contexto de sua escolha e, depois, na mobilização da criatividade para desenvolver o texto.

Como os estudantes tiveram liberdade para escolher o gênero do texto, o perfil de escolha quanto às notícias, reportagens, entrevistas e cartas, foi diferente para as turmas 301, 302 e 303 (TABELA 1):

\begin{tabular}{|c|c|c|c|c|c|}
\hline Turma & Cartas (C) & Entrevistas (E) & Notícias (N) & Reportagens (R) & Total (T) \\
\hline 301 & 6 & 3 & 10 & 5 & 24 \\
\hline $302^{*}$ & 15 & 4 & 1 & 3 & 23 \\
\hline 303 & 5 & 1 & 4 & 13 & 23 \\
\hline
\end{tabular}

Tabela 1 - Perfil de escolha pelo gênero textual para cada turma.

*Não consta na tabela um dos textos da turma 302, pois não foi avaliado, por não ter sido apresentado em nenhum dos gêneros solicitados.

Entendemos que isso se relaciona com a diversidade de perfis e interesses nas turmas e, portanto, não nos ateremos a definir qual dos gêneros textuais é mais favorável à contextualização. Também não nos parece essencial definir qual motiva mais a escrita ou com quais os estudantes pareceram gostar mais ou menos de trabalhar nas aulas de Química, uma vez que essa informação não poderia ser transposta para outros contextos.

Para escrever as notícias, reportagens e entrevistas, os alunos abordaram uma grande variedade de temas que não foram abordados em aula (QUADRO 2): 


\begin{tabular}{|l|c|}
\hline Temas & $\begin{array}{c}\text { Quantidade de } \\
\text { trabalhos }\end{array}$ \\
\hline Acidentes causados ao transportar produtos químicos & 6 \\
\hline O pH dos cosméticos para cabelo & 6 \\
\hline Desastres ambientais causados por atividades industriais & 4 \\
\hline Tratamento de água (piscina ou aquário) & 4 \\
\hline Variação do pH no corpo humano e possíveis doenças & 4 \\
\hline O pH de alimentos & 3 \\
\hline O pH no corpo humano & 2 \\
\hline Qualidade da água dos mananciais & 2 \\
\hline Poluição atmosférica e chuva ácida & 2 \\
\hline Explicação sobre o que é pH (pesquisa) & 2 \\
\hline Correção da acidez do solo para o plantio de hortênsias & 1 \\
\hline Uso inadequado de produtos do cotidiano e acidentes & 5 \\
\hline
\end{tabular}

Quadro 2 - Temas abordados nos trabalhos de notícias, reportagens e entrevistas.

Embora tenham sido entregues trabalhos muito bem estruturados, com linguajar adequado à área científica e dentro das normas cultas, não há como verificar a realização de plágio de notícias, reportagens e entrevistas já veiculadas em mídia digital ou impressa. Isso nos leva a direcionar o olhar para os trabalhos feitos no gênero carta, que têm caráter mais pessoal e não favorecem tanto a realização do plágio. O número de atividades feitas nesse formato nos surpreendeu, representando $37 \%$ do total de 70 trabalhos avaliados (GRÁFICO 1):

Total de textos agrupados por gênero

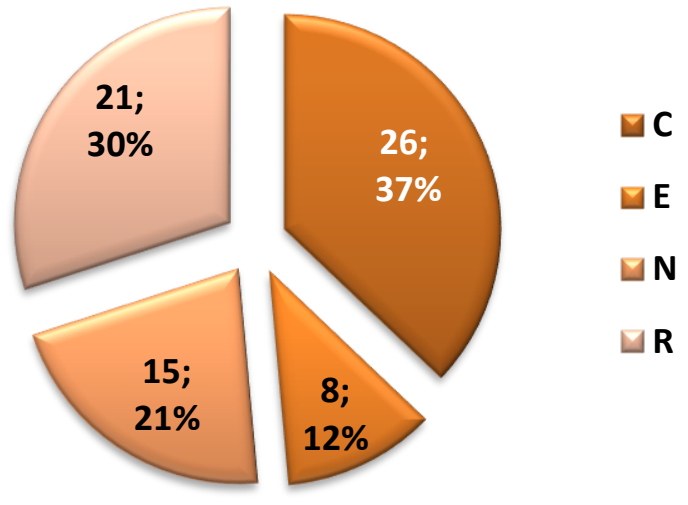


Selecionamos cinco dessas cartas para fomentar a discussão acerca da escrita e da criatividade no ensino de Química para refletir se essa atividade pode nos ajudar a contextualizar o conhecimento químico escolar.

Carta 1: o estudante se colocou na posição de um aluno do curso de Química que assistiu aulas sobre pH e conta a seu amigo o que entendeu sobre o tema. Para fazer isso, mobilizou tanto seu conhecimento químico quanto o saber oriundo de sua infância (FIGURA 1):

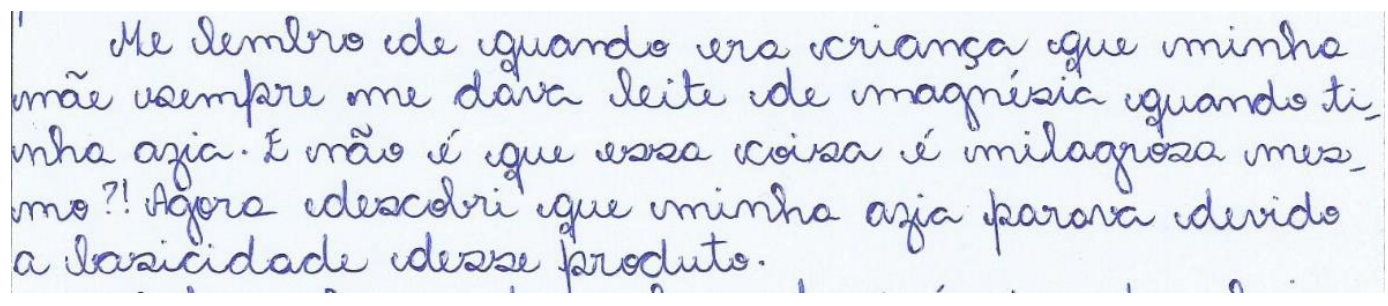

Figura 1 - Trecho da carta 1.

Nessa carta entendemos que o estudante conseguiu contextualizar seu conhecimento, uma vez que mesmo explorando bastante o conteúdo e a linguagem química ele estabeleceu relações diretas entre os conceitos químicos e sua realidade. $\mathrm{A}$ escrita de cartas permitiu, nesse sentido, criar condições criativas para uma contextualização que se opõe àquela na qual, apesar de aparentar uma proposta moderna para o Ensino de Química, "a essência permanece a mesma, priorizando as informações desvinculadas da realidade vivida pelos alunos e pelos professores" (RAMOS, 2011, p. 15).

Carta 2: a aluna escreveu sua carta e a enviou pelo Whatsapp, contando à sua mãe sobre um churrasco (Figura 2): 


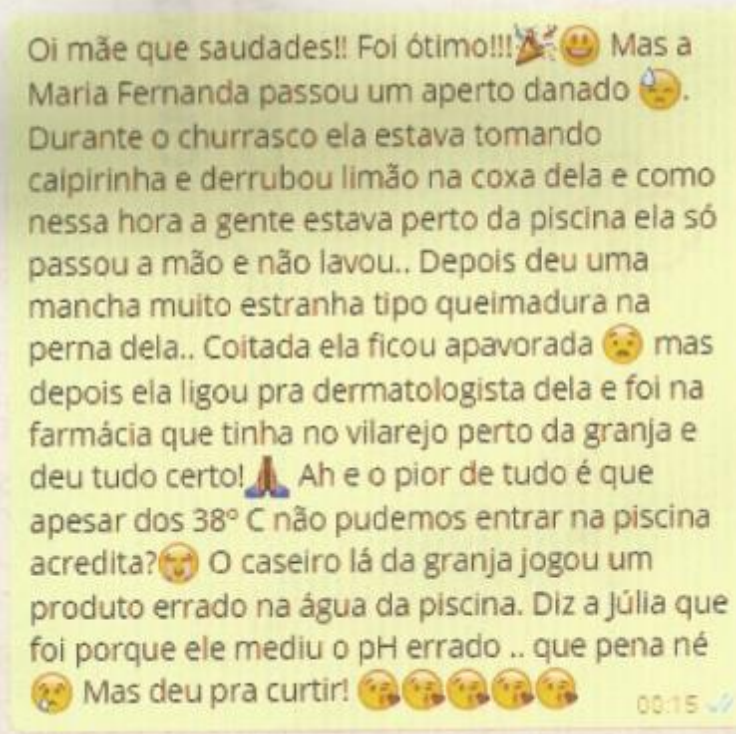

Figura 2 - Trecho da carta 2.

De todas as cartas, essa foi a única escrita no formato do aplicativo tão utilizado pelos alunos e professores das turmas atualmente. É interessante como a estudante mobilizou a criatividade para contar sua história, articulando a produção textual ao conhecimento químico numa situação cotidiana.

Apesar disso, a aula anterior e a escrita da carta não foram suficientes para que a estudante aplicasse seus conhecimentos químicos, por exemplo, para propor alguma solução para o problema de sua amiga com a queimadura ou para a água da piscina. Ainda assim, consideramos que a escrita de cartas foi eficiente em "retirar o aluno da condição de espectador passivo" (BRASIL, 1999, p. 91) e em "generalizar a contextualização como recurso para tornar a aprendizagem significativa ao associá-la com experiências da vida cotidiana ou com os conhecimentos adquiridos espontaneamente" (BRASIL, 1999, p. 94).

Carta 3: nessa carta, o aluno mobiliza os conhecimentos de química, a fim de informar e despertar a vontade de aprender em um amigo (FIGURA 3). Para isso, ele faz uma breve explicação sobre o potencial hidrogeniônico e a escala de pH. Em seguida, descreve o preparo de uma solução indicadora feita com repolho roxo, que poderia ser usada para verificar a acidez ou basicidade da água que se vai ingerir. 


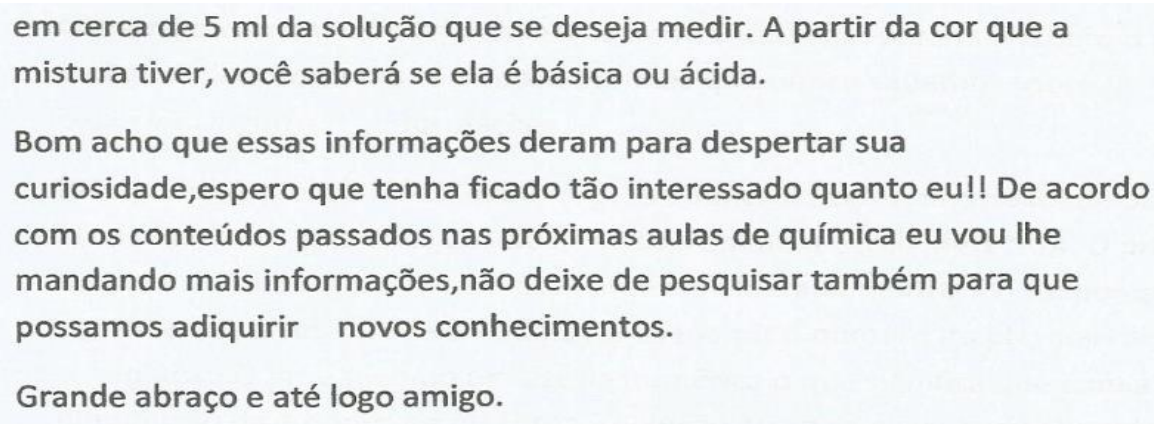

Figura 3 - Trecho da carta 3.

É interessante que o aluno tenha falado sobre o indicador feito com repolho roxo, pois ele não foi abordado em sala nem utilizado no laboratório. A atividade escrita foi capaz de mobilizá-lo na busca de conhecimento em outras fontes para enriquecer sua explicação. Nessa perspectiva, escrever cartas estimulou a curiosidade e a expressão de seus conhecimentos e interesses.

Carta 4: a estudante escreveu à sua mãe uma carta para explicar os cuidados ao fazer uso de sabonetes femininos íntimos (FIGURA 4).

você comprou aquele sabonete baratinho, sem nome, sem nada! A limpeza com esse tipo de sabonete é boa, já que eles tem caráter acido, ajudando a regular $\mathrm{opH}$ vaginal, diferente dos sabonetes normais que tem caráter básico ( com ph maior que 7 lembra?), então eles alteram o seu pH normal. Li outras entrevistas e reportagens de médicos especializados e ambos disseram que deve ser feita uma pesquisa sobre o $\mathrm{pH}$ do sabonete intimo usado e que ele não deve ser usado diariamente porque também pode alterar o $\mathrm{pH}$. A famosa frase do papai nunca fez tanto sentido "tudo em excesso faz mal". Muito complicado isso né mãe? Espero ter te ajudado, e realmente quero que você vá ao médico para que ele possa te indicar melhor qual o produto certo a ser usado.

Grande beijo, sua filha.

Figura 4 --- Trecho da carta 4.

Na carta, da qual foi retirado o trecho acima, foi possível perceber uma boa articulação entre escrita, criatividade e conhecimento químico, pois a aluna aplica seus conhecimentos para entender uma situação prática de seu cotidiano, mantendo a 
naturalidade. Além disso, aconselha cautela quanto ao uso do sabonete íntimo, o que nos remete a uma prática contextualizada que visa à formação cidadã e ao exercício do senso crítico (RAMOS, 2011, p. 22).

Carta 5: nesta carta, percebemos que a estudante, apesar de registrar na sua escrita as definições e a linguagem química para falar de diversas substâncias ácidas e básicas, não relaciona esse conhecimento com um contexto específico ou com algo do seu dia a dia. Lê-se em sua carta um texto técnico e impessoal (FIGURA 5):

\begin{abstract}
A delfinidina possui três anéis aromáticos, sendo dois condensados (juntos), e um outro separado. Essa união entre os anéis forma uma estrutura em que existe considerável deslocalização eletrônica, ou seja, os elétrons $\pi$ desses anéis não estão presos em suas ligações, mas estão em constante movimento. Para que seja possível essa deslocalização eletrônica é necessário que os elétrons absorvam energia. No caso da delfinidina, a energia absorvida está na região do visível no espectro solar, e como consequência, as substâncias que possuem essa molécula são coloridas. Normalmente substâncias que possuem várias ligações $\pi$ conjugadas apresentam cores intensas, e por isso, os grupos responsáveis por essa absorção de luz são chamados cromóforos. A delfinidina presente nas pétalas da hortênsia não é a única molécula que apresenta esse grupo cromóforo. Na verdade a delfinidina faz parte de uma grande família de moléculas chamadas de antocianinas. As antocianinas são moléculas que apresentam como grupo cromóforo a estrutura de dois anéis aromáticos condensados (um deles com o axigênjo) e outro anel mais afastado, e são responsávejs pela coloraça vermelha, roxa, ou azulada de vários vegetais como a uva, o repolho roxo, as amoras etc.
\end{abstract}

Figura 5. Trecho da carta 5.

O movimento realizado na Carta 5, que traz diversas informações, não relaciona o conhecimento com algum contexto específico, sendo estabelecidas relações somente no campo da exemplificação. No entanto, para que seja realizada uma contextualização, desenvolver as definições e termos científicos não é suficiente, pois ao se situar somente no campo da citação de fatos em que o conhecimento químico se aplica, o estudante não estabelece relações significativas com sua realidade (SILVA, 2007, p. 22).

Devemos mencionar que, devido às provas de fim de ano e preparações para concursos, não houve tempo suficiente para dar o retorno das atividades aos estudantes nem a possibilidade de reescrever as cartas. Gostaríamos de ter feito isso por acreditarmos que, nesse caso, os conhecimentos acerca de $\mathrm{pH}$, acidez e basicidade, teriam sido melhor contextualizados pelas turmas com as quais trabalhamos. 
O que nos parece atraente em tais atividades de escrita é que podem subsidiar a escolha de temas para a contextualização, especialmente em turmas bastante heterogêneas quanto aos interesses e contextos sociais. Nessa perspectiva, o estudante é quem inicia a contextualização, o que permite que os docentes se guiem por caminhos mais próximos de suas turmas. A intervenção nos mostrou muito claramente a necessidade de levar em consideração as vivências dos estudantes para propor a contextualização no Ensino de Química e que criar espaços para a escrita criativa é um bom meio de iniciar a construção das relações entre conhecimento químico e realidade. Porém, muitas vezes, o estudante não conseguirá finalizar a construção de tais relações, sendo necessária a mediação do professor. Isto é, o fato de alguns alunos conseguirem estabelecer tais relações não nos deve induzir a deixar a contextualização a cargo do estudante, sendo interessante que o professor retome as atividades escritas com a turma para melhor apropriação e contextualização da Química.

Algo que foi recorrente e inesperado nas cartas foi o fato dos discentes expressarem suas dúvidas quanto a novos saberes. Assim, a escrita de cartas ocupou ainda outra importante dimensão do processo de ensino-aprendizagem: a de proporcionar o diálogo entre professor e aluno. Nesse espaço, pudemos identificar novas necessidades e possibilidades para as turmas como, por exemplo, repensar as avaliações escritas, visto que

é necessário estar atento ao reconhecimento dessas formas de pensar dos alunos, respeitando-as, pois são elas que possibilitam traçar estratégias de ensino que permitem a construção da visão científica, através da confrontação do poder explicativo de seus modelos intuitivos com aqueles elaborados pela ciência. (BRASIL, 2002, p. 81)

Embora nem todos os alunos tenham entregado as atividades escritas, não houve resistências à proposta, o que atribuímos ao contexto militar da escola, que restringe muito as práticas avaliativas realizadas pelos professores, bem como as práticas comportamentais dos alunos. Nessa perspectiva, foi mais "fácil” propor algo que, em outros contextos, poderia fomentar alguma resistência explícita por parte das turmas. 


\section{Considerações finais}

Entendemos que atuar no Ensino Médio é, entre tantas outras tarefas, assumir posição de questionar o estabelecido para compreender que as coisas não são simplesmente dadas no mundo, mas sim construídas, o que é válido inclusive para as relações entre conhecimento escolar e realidade, mediados ou não pela criatividade. “Nesse sentido, deve ser levado em conta o que os estudantes já sabem, o que eles gostariam de aprender e o que se considera que precisam aprender" (BRASIL, 2013, p. 181).

Os textos entregues pelos discentes nos permitiram atingir, em maior ou menor escala, alguns objetivos principais da intervenção: conhecer as ideias prévias dos estudantes sobre $\mathrm{pH}$, acidez, alcalinidade e neutralidade de soluções; ajudar o estudante a compreender que a aprendizagem pode ocorrer tanto de forma tradicional quanto de maneira criativa, motivando-os na busca de novos meios para adquirir conhecimentos; promover reflexões sobre o caráter das soluções do cotidiano e suas propriedades; e desenvolver e valorizar habilidades próprias a cada estudante, por meios de diferentes produções textuais. Além de constituir um bom meio para o aluno se apropriar dos conceitos adquiridos e ser capaz de aplicá-los em diferentes contextos e de nos ajudar a ressaltar a importância da escrita na construção do conhecimento.

Acreditamos que as atividades, aqui descritas, têm potencial para desenvolver uma aprendizagem de qualidade acerca do conteúdo e para além dele, podendo ser repensadas e reestruturadas conforme as necessidades da turma para serem realizadas em outros contextos escolares. Trabalhar com notícias, reportagens, entrevistas e cartas constituíram uma boa tentativa para estimular a criatividade e desenvolver escrita e leitura nas aulas de Química. E, seja para contextualizar algum conhecimento e/ou para realizar uma avaliação não tradicional, podem fazer parte de um cenário de aprendizagem significativa, no qual "uma nova informação (um novo conhecimento) se relaciona de maneira não arbitrária e substantiva (não-literal) à estrutura cognitiva do aprendiz" (MOREIRA, 2011 p. 26). 
Os alunos são parte de um universo muito maior que a escola, complexo e cheio de desafios e, por isso, soluções criativas serão sempre necessárias em suas vidas. Como alerta Alencar (2002), o desejo de usar a criatividade pode se atrofiar ao longo de um processo escolar que não a inclua e a prática de ensinar respostas "corretas" pode contribuir para erradicar a natural curiosidade e imaginação do ser humano, que se apropria do conhecimento mais efetivamente,

por práticas experimentais, com contextualização que relacione os conhecimentos com a vida, em oposição a metodologias pouco ou nada ativas e sem significado para os estudantes. Estas metodologias estabelecem relação expositiva e transmissivista que não coloca os estudantes em situação de vida real, de fazer, de elaborar. (BRASIL, 2013, p. 167)

Assim, propor atividades criativas e de escrita no Ensino de Química - em diferentes formatos, momentos e objetivos - pode nos ajudar, ainda, a repensar a avaliação escrita tradicional para, quem sabe, desenvolver outras que possam contribuir significativamente para o processo de formação dos jovens na escola.

\section{Referências}

ALENCAR, Eunice Maria Lima Soriano. Criatividade no contexto educacional: três décadas de pesquisa. Psicologia: Teoria e Pesquisa, v. 23, n. especial, p. 45-49, 2007.

ALENCAR, Eunice Maria Lima Soriano. O contexto educacional e sua influência na criatividade. Linhas Críticas, v. 8, n. 15, p. 165-178, 2002.

BRASIL. Ministério da Educação. Diretrizes Curriculares Nacionais Gerais da Educação

Básica. Brasília, DF: MEC, SEB, DICEI, 2013.

BRASIL. Ministério da Educação. Parâmetros Curriculares Nacionais + (PCN+) - Ciências da Natureza e suas Tecnologias. Brasília: MEC, 2002. 
BRASIL. Ministério da Educação. Parâmetros Curriculares Nacionais do Ensino Médio. Brasília: MEC; SEMTEC, 1999.

FLÔR, Cristhiane Cunha. Leitura e formação de leitores em aulas de Química no Ensino Médio. Florianópolis; UFSC, 2009, 235 p. Tese (doutorado) - Programa de Pós-Graduação em Educação Científica e Tecnológica, Universidade Federal de Santa Catarina, Florianópolis, 2009.

\section{GIRALDI, Patricia Montanari. Leitura e escrita no ensino de ciências: espaços para} produção de autoria. Florianópolis: UFSC, 2010, 350 p. Tese (doutorado) - Programa de Pós-Graduação em Educação Científica e Tecnológica, Universidade Federal de Santa Catarina, Florianópolis, 2010.

MOREIRA, Marco Antônio. Aprendizagem significativa: um conceito subjacente. Aprendizagem significativa em revista. Meaningful Learning Review, v. 1, n. 3, p.25-46, 2011.

NAKANO, Tatiana de Cássia. O percurso da criatividade figural do ensino médio ao ensino superior. Boletim de Psicologia, v. 56, n. 125, p. 205-219, 2006.

QUEIROZ, Salete Linhares. A linguagem escrita nos cursos de graduação em química. Química Nova, v. 24, n. 1, p. 143-146, 2001.

RAMOS, Rafael Rodrigues. A contextualização do ensino nas aulas de química no $3^{\circ}$ ano do ensino médio: experiências com limites e possibilidades baseados na concepção de Paulo Freire. 2011. 47 p. Trabalho de Conclusão de Curso (Licenciatura em Química) Unidade Universitária de Ciências Exatas e Tecnológicas, Universidade Estadual de Goiás, Anápolis, 2011.

SILVA, Erivanildo Lopes. Contextualização no ensino de química: ideias e proposições de um grupo de professores. 144 p. 2007. Dissertação (Mestre em Ensino de Ciências) Instituto de Física, Instituto de Química, Instituto de Biociências e Faculdade de Educação, Universidade de São Paulo, São Paulo, 2007.

SOUZA, Suzane Cassiani; ALMEIDA, Maria José Pereira Monteiro. Escrita no Ensino de Química: autores do Ensino Fundamental. Ciência \& Educação, v. 11, n. 3, p. 367-382, 2005.

WARTHA, Edson José; SILVA, Erivanildo Lopes; BEJARANO, Nelson Rui Ribas. Cotidiano e contextualização no ensino de química. Química Nova na Escola, v. 35, n. 2, p. 84-91, 2013. 
Recebido em: 31/07/2016 Aprovado em: 30/10/2016

Universidade do Estado de Santa Catarina - UDESC Centro de Ciências Humanas e da Educação - FAED

Revista PerCursos

Volume 17 - Número 35 - Ano 2016 revistapercursos@gmail.com 